\title{
Cardiac development after salvage partial left ventriculectomy in an infant with anomalous left coronary artery from the pulmonary artery
}

\author{
Stephen Westaby, PhD, MS, FETCS, FECS, FACC, ${ }^{a}$ Nick Archer, MD, ${ }^{b}$ and Saul G. Myerson, MD, MRCP, FESC, ${ }^{c}$ Oxford, \\ United Kingdom
}

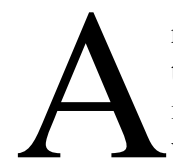

nomalous left coronary artery from the pulmonary artery (ALCAPA) is an unusual cause of heart failure in infancy. ${ }^{1}$ At this stage, left coronary blood flow is reversed with steal into the pulmonary artery. Repeated episodes of myocardial ischemia or infarction cause globally impaired left ventricular function and may substantially increase the risk of surgical correction. In this report, we provide late followup on an infant with ALCAPA who, after coronary reimplantation, could not be separated from cardiopulmonary bypass without further intervention.

\section{Clinical Summary}

A 5-month-old girl had heart failure manifested by breathlessness and failure to thrive. Echocardiography demonstrated severely impaired left ventricular function and mitral regurgitation, and coro-

From the Departments of Cardiothoracic Surgery, ${ }^{\mathrm{a}}$ Paediatric Cardiology, and Cardiovascular Medicine, ${ }^{\mathrm{c}}$ University of Oxford, John Radcliffe Hospital, Oxford, United Kingdom.

Received for publication Sept 27, 2007; accepted for publication Oct 15, 2007.

Address for reprints: Prof. Stephen Westaby, PhD, MS, FETCS, FECS, FACC, Consultant Cardiac Surgeon, Department of Cardiothoracic Surgery, John Radcliffe Hospital, Headley Way, Oxford OX4 3AU, United Kingdom (E-mail: stephen.westaby@orh.nhs.uk).

J Thorac Cardiovasc Surg 2008;136:784-5

$0022-5223 / \$ 34.00$

Copyright (C) 2008 by The American Association for Thoracic Surgery

doi:10.1016/j.jtcvs.2007.10.085 nary angiography showed ALCAPA. An operation was performed to connect the left coronary ostium with the aorta using flaps derived from the pulmonary artery and aorta. These flaps extended the left main stem. ${ }^{2}$ Although cardioplegic solution was delivered to both right and left coronary arteries, myocardial contractility was poor after reperfusion and the heart could not sustain systemic blood flow. No infant circulatory support device was available. After 2 hours of supportive perfusion and several abortive attempts to discontinue cardiopulmonary bypass, a radical salvage procedure was attempted. Partial left ventriculectomy was performed by excising around $25 \%$ of the left ventricular circumference in the circumflex coronary territory (Figure 1,a). The myocardium showed endocardial fibrosis and diffuse scar formation. An Alfieri suture was applied to the mitral valve to reduce severe mitral regurgitation. Cardiopulmonary bypass was discontinued with the reconstructed heart (Figure 1,b) and the infant survived.

Now aged 10 years, she is in New York Heart Association class I, participates in sport, and has normal physical and intellectual development. In view of her unrestricted lifestyle, a cardiovascular magnetic resonance scan was performed to assess left ventricular function and patency of the reconstructed left main coronary artery. The coronary artery had a higher than usual origin from the left lateral aspect of the aorta, but normal flow (Figure 2). The previously dilated right coronary artery had reverted to normal caliber. Left ventricular ejection fraction was $47 \%$ with normal end-systolic and end-diastolic volume indices for her age. There was mild distal anterior hypokinesia and minimal mitral regurgitation through the dual-orifice valve. The linear scar at the site of the ventricular anastomosis was the only clear sign of the myocardial resection. We
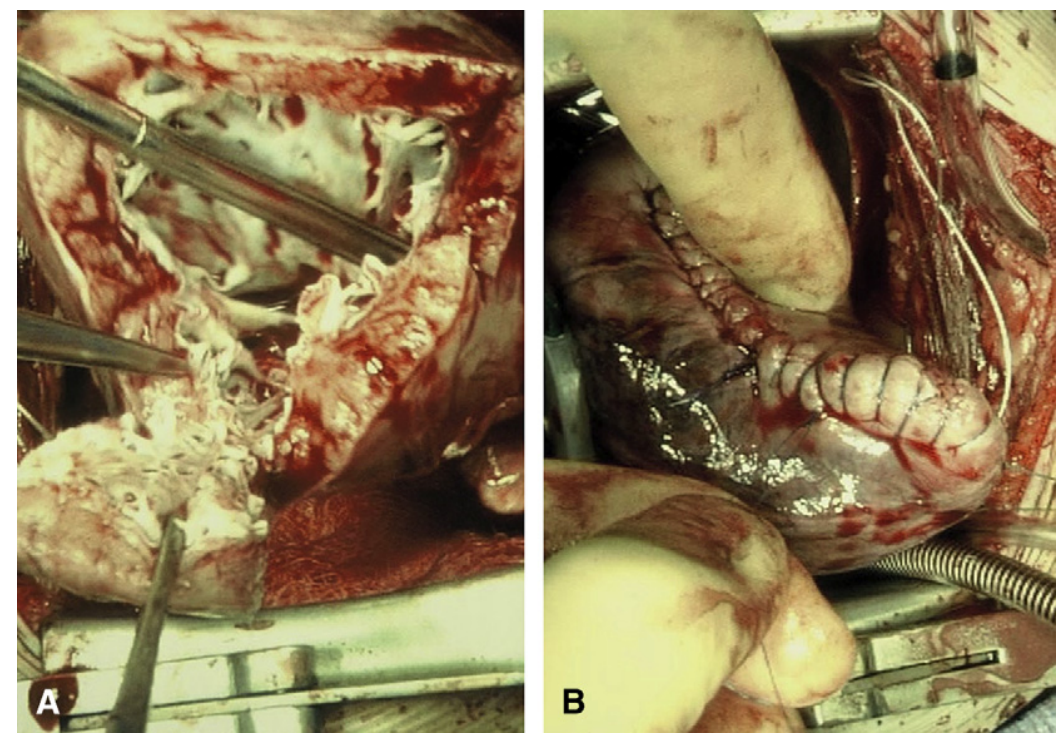

Figure 1. Intraoperative images at age 5 months. a, Removal of full thickness myocardium. Note the white appearance of the infarcted subendocardial layer in other areas of the heart. $b$, External appearance once reconstructed. 

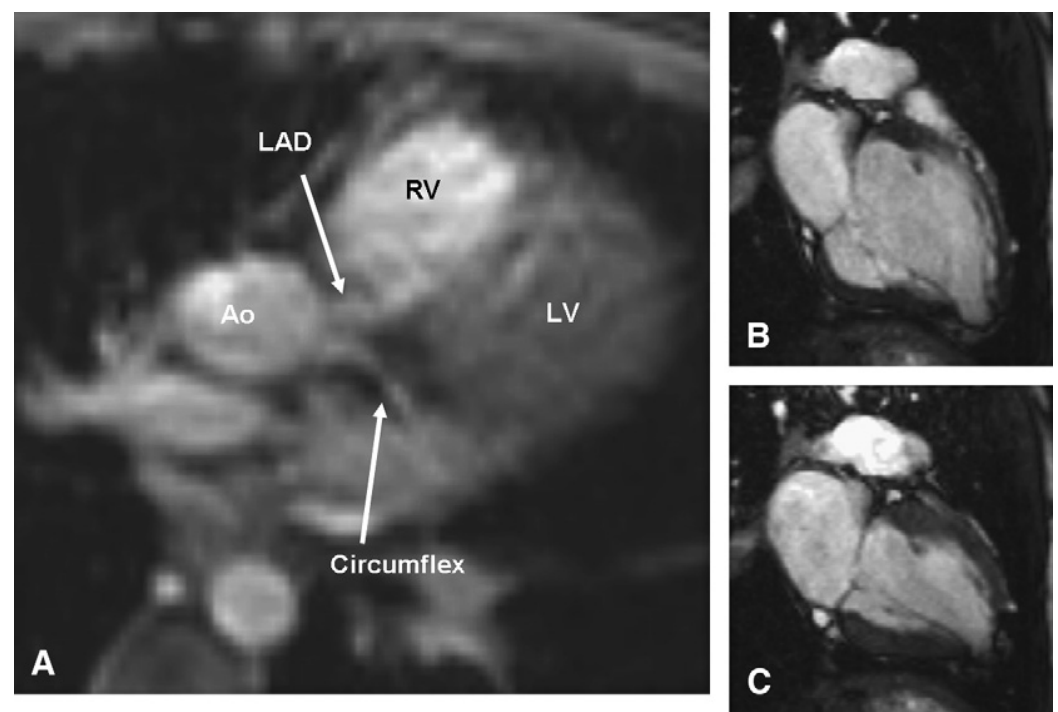

Figure 2. Cardiovascular magnetic resonance images at age 9 years: a, The reconstructed left coronary artery arising from the aorta; $b$ and $c$, Vertical long-axis (2-chamber) view demonstrating near normal cardiac function in diastole and systole, respectively. Images are still frames from steady-state free-precession (TrueFISP) cine images with electrocardiographic gating and breath-hold on a Siemens Sonata scanner (Erlangen, Germany); field of view $340 \times 340 \mathrm{~mm}$;

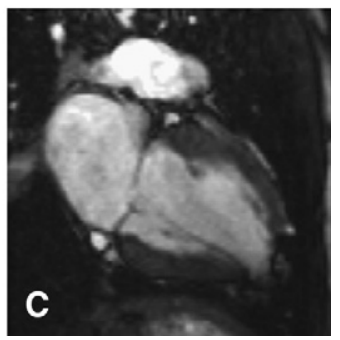
repetition time 3.08; echo time 1.54 seconds; slice thickness $6 \mathrm{~mm}$; flip angle $60^{\circ}$. Ao, Aorta; Circumflex, circumflex coronary artery; $L A D$, left anterior descending coronary artery; $L V$, left ventricle; $R V$, right ventricle.

considered this remarkable result to indicate that the infant heart has regenerative capacity not found in adult ischemic and scarred myocardium.

\section{Comment}

There is little follow-up information regarding left ventricular structure late after repair of ALCAPA in infancy. Surgical and 30-day mortality are substantial for these infants. ${ }^{3}$ Because of this, the deployment of circulatory support devices has been advocated to sustain the systemic circulation during postischemic myocardial stunning. ${ }^{4}$ In patients with full-thickness scar and a dyskinetic anterior wall, left ventricular aneurysmectomy has been performed. ${ }^{5}$ In contrast, this child had a Batista-type partial left ventriculectomy through scarred but full-thickness myocardium in a last attempt to sustain life. ${ }^{2}$ The change from a globular left ventricle to the elliptical shape succeeded, but the very satisfactory outcome of the long-term remodeling process was unexpected. Encouraged by this result, we would consider the same approach in a similar life-threatening situation.

\section{References}

1. Arciniegas E, Farooki ZQ, Hakimi M, Green EW. Management of anomalous left coronary artery from the pulmonary artery. Circulation. 1980; 62(2 Pt 2):1180-9.

2. Katsumata T, Westaby S. Anomalous left coronary artery from the pulmonary artery: a simple method for aortic implantation with autogenous arterial tissue. Ann Thorac Surg. 1999;68:1090-1.

3. Lange R, Vogt M, Horer J, Cleuziou J, Menzel A, Holper K, et al. Long term results of repair of anomalous origin of the left coronary artery from the pulmonary artery. Ann Thorac Surg. 2007;83: 1463-71.

4. del Nido PJ, Duncan BW, Mayer JE Jr., Wessel DL, LaPierre RA, Jonas RA. Left ventricular assist device improves survival in children with left ventricular dysfunction after repair of anomalous origin of the left coronary artery from the pulmonary artery. Ann Thorac Surg. 1999; 67:169-72.

5. Turina M, Real F, Meier W, Senning A. Left ventricular aneurysmectomy in a 4-month-old infant: alternative method of treatment of anomalous left coronary artery. J Thorac Cardiovasc Surg. 1974;67: 915-9. 